\title{
Horse Antithymocyte Globulin/Tacrolimus Regimen
}

National Cancer Institute

\section{Source}

National Cancer Institute. Horse Antithymocyte Globulin/Tacrolimus Regimen. NCI

Thesaurus. Code C160511.

A regimen consisting of horse antithymocyte globulin and tacrolimus that can be used for the prevention and treatment of acute rejection following organ transplantation. 